\title{
Knitting Practice in Korea: A Geography of Everyday Experiences
}

\author{
Hye Young Shin \\ Ph.D. candidate, Department of Clothing and Textiles, Seoul National University \\ 222-205, Seoul National University, Shillim-dong, Kwanak-gu, Seoul, South Korea \\ Tel: 82-10-6717-3803 E-mail: dublin11@naver.com \\ Ji Soo Ha (Corresponding author) \\ Professor, Department of Clothing and Textiles, Seoul National University \\ 222-205, Seoul National University, Shillim-dong, Kwanak-gu, Seoul, South Korea \\ Tel: 82-2-880-1453Ｅ-mail: jisooha@snu.ac.kr
}

\begin{abstract}
The recent resurgence of knitting is an ambiguous social phenomenon because it has pre-industrial connotations in late modern society. Knitting is inherently an ambiguous practice which blurs the boundary between production and consumption, the material and the mental and subject and object. This paper explores Korean knitting practice from the angle of social practice. An examination of knitting practice in Korea revealed that the inherent heterogeneity is intricately intertwined with the complex landscape of knitting practice, which is dispersed in a range of different forms of subgroups. Also, the multifaceted aspect of these subgroups which combines consumption, production, education and socialization, refers to the complicated and contrasting aspects of contemporary consumption and consumers. This paper particularly pays attention to the role of practical understanding as a form of skill, know-how and knowledge in the formulation and transformation of knitting practice. It also examines the emotional landscape of knitting practice, which is constructed and mediated in close interconnection with the material dimensions of the practice.
\end{abstract}

Keywords: Consumers, Embodied experiences, Knitting, Korea, Practical understanding, Practice

\section{Introduction}

Knitting is not only a craft production but also a form of consumption, which generates a demand for mass-produced materials. The resurgence of knitting with pre-industrial associations is an ambiguous phenomenon but has an increasingly noticeable presence in late modern society, which has undergone the decline of craft production and a clear division between production and consumption. Knitting in Korea, also, after experiencing turbulent times (Note 1) in the midst of the overwhelming effects of the rapid industrialization in the late $20^{\text {th }}$ century, has now regained a visible presence (Note 2) but with a very complex landscape.

Knitting is composed of some basic elements: the purchase of materials, designing, physical labor, and the production of material goods. The inherent heterogeneity of knitting, which integrates consumption and production and mental activity and physical activity, generates its unique and ambiguous characteristics and status. This complexity of knitting is connected with the multifaceted aspect of knitting culture, which defies the conventional distinction between consumption and production, subject and object, the material and the mental and the symbolic and the practical.

Knitters, ambiguous figures who cross these established boundaries, can be understood in the context of the recent problematization of the bi-polarized conceptualization of the consumer either as the 'autonomous' agent or 'passive' recipient of external conditions (Williams, 2004; Warde, 2005; Slater, Miller, 2007; Watson, Shove, 2008). The subversion of the prevalent notions of the consumer may correspond to the emerging academic attention to the conflation of consumption and production and the theorization of the consumer as a more complex and contrasting figure (Sheller, 2004; Cambell, 2005; Warde, 2005). In this context, an examination of knitters relates to the complexity and dynamics of everyday life in a world increasingly pervaded by the powers of commerce, which can be approached more closely and adequately by overcoming many persistent dualisms, for example, that between consumption and production, 'humanity and materiality' or 'subject and object' (Miller, 2005). 
Existing academic literature on knitting has been mainly concerned with the cultural contexts of the alternative or subversive potential of knitting (Parkins, 2004; Minahan, Cox, 2007; Myzelev, 2009). However, multiple layers of relations, interactions and meanings are bound up with one another in this seemingly mundane activity. In this context, it would be also essential to consider that knitting is an everyday activity of which knitters' corporeal experiences constitute an integral part to get a closer glimpse of this multifaceted and dynamic social phenomenon. Thus, this paper examines Korean knitting culture with a particular focus on its 'embodied, materially mediated' (Schatzki, Cetina \& Savigny, 2001:2) dimension, drawing on theories of social practice. To explore the everyday embodied experiences of knitters, a particular emphasis is placed on investigating how practical understanding as a form of skill, know-how or knowledge is distributed and shared in the complicated geography of the practice and how the emotional landscape is formulated in connection with physical performances and material conditions constituted in knitting practice.

The research is primarily based on interviews (Note 3) with knitters from a range of different forms of subgroups such as internet knitting communities, wholesale knitting shops, retail knitting shops, craft classes at local community centers or at department stores, or independent knitters. A total of 28 interviewees consisted of women in their 20s to $80 \mathrm{~s}$ who resided in Seoul and surrounding areas. The interviewees consisted of knitting shop owners, knitting instructors and knitting yarn importers. In addition, an observation of internet knitting communities, wholesale knitting shops and retail knitting shops was undertaken.

\section{Embodied Social Practice}

As the overwhelming effects which enhanced individuality, globalization or commodification have on contemporary social life testify, it is undeniable that social life is heavily framed by wider cultural, social and historical contexts. While acknowledging the importance of an analysis of these wider contexts in formulating, mediating and transforming everyday life, this paper proposes that it is also crucial to take lived experiences into consideration as a key element for a more nuanced understanding of contemporary social life.

A recent increase in academic attention to an analysis of social practices illustrates the growing interest in embodied human experiences. Practice theories, which emphasize embodied human action, prioritize the unconscious, routine and habitual aspect of social action and the interconnection between human behavior and its material environments (Gronow, Warde, 2001; Reckwitz, 2002; Dante, 2004; Warde, 2005). In practice theories, the body is perceived as critical as 'the common meeting point of mind and activity and of individual activity and society' (Schatzki, Cetina \& Savigny, 2001:3). Hence, the close interconnection between the bodily activities, mental activities and emotional states of humans and non-human objects is an essential presupposition (Reckwitz, 2002: 249).

The inseparability of bodily and mental activities points to the importance of practical understanding embedded in the body as a form of skill, know-how and knowledge. They are understood as crucial in 'the persistence and transformation of social life' as 'a battery of bodily abilities that results from, and makes possible, participation in practices' (Schatzki, Cetina \& Savigny, 2001:3, 9). The tacit and unconscious knowledge inscribed in corporeal experiences is particularly important because it plays a critical role in the constitution of motivations and organizations of projects in social practice as illuminated in Watson and Shove's (2007) analysis of the role of competence in the formulation of new projects. Reckwitz (2002) links knowledge with 'a particular routinized mode of intentionality, i.e. of wanting or desiring certain things and avoiding others'(254). This indicates that practical understanding distributed and shared in a particular practice underpins the basis and dynamics of the social practice. Reckwitz (2002) also proposes the existence of the 'practice-specific emotionality' (254). Academic researches on emotions and their close relation with material conditions claim that feelings and emotions are not just located within the individual sphere but also closely connected to the characteristics and qualities of social practice. For example, Sheller (2004) attempts to show that 'emotions arise out of particular material relations and sensations' in her exploration of the relation between a human and a car (223).

Knitting is also an embodied and materially mediated practice formed around the close relationship between the physical, mental and emotional dimensions of knitters, who are deeply entrenched in the material environments of the practice. Particularly the way in which knitters' 'skilled body' is developed and reproduced is a crucial factor in formulating the contemporary knitting landscape. Also, knitters' experiences of particular feelings and emotional states that constitute the characteristics of knitting practice are closely related to knitters' corporeal engagements with the practice. 


\section{Practical Understanding and Geography of Knitting Practice in Korea}

\subsection{Complicated Landscape of Korean Knitting Practice}

Rapid industrialization in Korea has changed the face of knitting practice significantly. Until the 1980s, when the mass-production of clothing was not prevalent, knitting was mainly practiced as a practical way of obtaining clothes due to the scarcity of good quality clothing products and the high prices of customized clothing items. (Note 4) However, clothes have become abundant with the growing mechanization of clothing production and the import of cheap foreign clothing since the 1980s. The meanings of hand knitting have become more multifarious in a situation where machine-produced knit clothing items are easily available and have become cheaper options. Hand knits have increasingly been equated with a marker of lifestyle choices, tastes, or individual identity and its implication of economic and practical choices has weakened. Due to high yarn prices and the considerable amount of time required for manual labor, knitting has come to be associated with a middle class leisure activity reserved for those with a substantial disposable income and a fair amount of leisure time. The mixture of leisure and material production through physical performances implied in knitting has produced an interesting array of significations and corporeal experiences.

The case of one knitter who regularly visits a local knitting shop illustrates the multiplicity of knitters' expectations, purposes, and experiences in current knitting practice. Her engagement in knitting is formulated and mediated by the combination of motivations and considerations based upon social relations built upon similar social capital, compromise between practicality and personal tastes and corporeal experiences.

"It stops my brain from being busy with unnecessary worries and keeps me focused. I come to this shop to spend quality time with nice people who have good taste and wisdom. People here have an eye for good designs... Knitting is different from housework, which is an endless chore with no visible signs of accomplishment.... I don't like cheap machine-made knits but high-end brand ones are too expensive. So I reproduce those designs myself with some variations using good quality materials."

The complexity implied in knitters' involvement in knitting practice can be understood as being connected with the complicated geography of knitting practices in Korea. Knitting is distributed in a range of different forms of groups and organizations such as internet communities, wholesale knitting shops, retail knitting shops, craft classes at local community center or at retail chains, or individual knitters in Korea. Overall, knitting skills are disseminated and shared through an array of knitting subsets of multifarious nature where the functions of consumption, production, socialization and education are entangled.

\subsection{Distribution of Practical Understanding in Korean Knitting Practice}

Wholesale knitting shops have been a major feature of Korean knitting practice along with retail knitting shops. About 70 wholesale knitting shops are concentrated in the Dongdaemun Jonghap Market in Seoul, the biggest market for clothing materials in Korea, and which draws knitters across the country. These shops, which used to deal only with manufacturers or retailers until the late 1990s, now sell knitting materials in wholesale packages to individual knitters who visit wholesale shops for low-priced and a good assortment of knitting materials. A shop owner in the Dongdaemun Jonghap market, who has been in business for 30 years in the market, gives an account of the transformation of wholesale knitting shops.

"Before the economic crisis in 1997 (Note 5), we only sold yarn to knit manufacturers, like socks manufacturers. Falling sales and the popularity of hand knits at that time made us turn to individual knitters. Now, they form the staple of our sales."

These knitting shops offer free knitting lessons and regularly feature new seasonal clothing or accessory samples for knitters to copy or adjust according to individual tastes and needs. All this is intended to keep knitters motivated and to encourage them to continue with new projects. Some knitters adopt or adjust provided samples, and some knitters bring specific designs to instructors and ask for professional advice in executing the designs. Also, knitters share feedback on the colors and silhouettes of each other's work at knitting shops. Knitters depend on instructors, particularly heavily for gauging, which knitters consider the most crucial and tricky part of knitting projects and requires a fairly good amount of accumulated knowledge and experience to have a good command of the skill.

Retail knitting shops which are scattered in local resident areas operate in a similar way, performing a role as a major channel of disseminating skills, know-how and knowledge. The only noticeable difference between the wholesale and retail knitting shops is the minimum sales unit of yarn. Whereas shops in the wholesale markets only sell yarn in bulk, knitting shops sell a single ball of yarn as well. Knitters spend hours in knitting shops, performing many actions simultaneously such as buying materials, consulting, knitting, or socializing with other 
knitters. Some knitters have a wealth of experience and the ability to interpret patterns from knitting magazines or books and skills to execute designs without much help. However, the convenience of obtaining yarn, professional help, information on changing fashion trends or finishing services for accessory items such as bags provided at knitting shops, draws these experienced individual knitters to knitting shops.

Craft classes at community centers or at department stores or discount store chains also serve as a point of entry into or provide motivation for continued involvement in knitting. Many of the major retail chains in Korea provide craft programs for customers at cheap prices for promotional purposes. Instructors at these kinds of knitting classes provide lessons and solutions for the specific needs of students and also offer the service of buying knitting materials from wholesale dealers for students.

Instructors from community center and department store craft classes interviewed point to the disparity among knitters in the duration of and degree of motivation for skill learning, which they consider a major obstacle for the stability and expandability of the practice. The view of an instructor at a department store with over 40 years of experience as a knitting instructor suggests that the acquisition and development of basic practical understanding is essential for the continued participation of knitters and persistence of a particular practice.

"Some people are too busy with other things or are not that patient, so they give up quickly just after taking a few classes. But those who are consistent in coming to classes and learning skills tend to stick to knitting very long, usually for more than ten years."

\subsection{The Role of Practical Understanding in the Formation of On-line Knitting Practice}

The spread of the internet has transformed and complicated the Korean knitting landscape considerably. As knitting materials have increasingly come to be available over the internet, some knitters have migrated from knitting shops to internet knitting communities for practical information. And new knitters are being recruited through online knitting practice. In 2010, Naver (http://www.naver.com) and Daum (http://www.daum.net), the two largest internet portal sites in Korea, have 11 registered communities devoted to knitting with more than one thousand members respectively, and the two largest knitting communities at daum have more than 60 thousand members each.

The convenience in accessing knitting instructions, knitting patterns and trends is a major advantage of using internet knitting communities. Internet knitting communities usually have open libraries containing knitting patterns and illustrated or video instructions, and they expand these libraries by allowing members to post their own sources that have been obtained elsewhere. Members also exchange evaluations of knitting materials such as yarn, needles or books in the market based on personal experiences. Personal blogs that are linked to community pages are also used as a source of acquiring learning materials for knitting. These communities also work as a social space for members to share experiences, tips, chit-chats, and the appreciation or encouragement of the knitting projects of other members. An interesting feature of online knitting practice is that some knitting community sites are linked with shopping pages usually run by community site owners. The commercial function capitalizing on social networks renders the nature of knitting communities even more complicated and ambiguous.

The lack of real time interactivity and tangibility in the process of communicating information over the internet at this stage of interactive technology imposes limitations on the effective circulation of knowledge. When faced with the need for improving their skills or finding solutions for their specific needs, some knitters set out to seek face-to-face instruction. The regular off-line meetings of community members held at public places such as coffee shops provide a chance to extend knowledge and improve skills. This can be viewed as an effort to internalize shared understanding into the techniques of the body of an individual. An internet knitting community member chooses to gain more detailed and specified advice and solution at offline meetings.

"It is hard to move up to a higher level if you only consult internet sources. They are not detailed and informative enough to take you to another level. You need to get help from teachers and your fellow knitters in person to really improve your skills."

Knitters bring their current projects and exchange advice and feedback, especially from community owners who are likely to be the most experienced and equipped with expertise. These regular meetings, which are likely to be composed of the most active participants of the knitting community, also provide a chance for knitters to build close relationships with other knitters.

However, an internet knitting community and shopping mall owner comments on the existence of the different levels of participation among community members, evidenced by the fluctuation of the number of participants.

This asymmetrical feature leads to the seasonal gap in terms of participation and sales volume between the 
summer and the winter. With the development of summer knitting yarns, knitting, which was once regarded as an exclusively winter activity, is now widely practiced also in the summer. However, all the knitting instructors interviewed are of the opinion that in the winter, participation and sales increase significantly because the demand for winter accessory items such as mufflers or neck warmers for the knitters themselves or for gift purposes rises noticeably. The increase of demand for simple winter items that do not require much time or a high level of skill suggests the considerable proportion of casual knitters who stay in and out of the practice due to changing weather conditions and fashion trends.

Knitting packages that form the main products of internet shopping malls are specifically aimed to cater to the demands of beginners or casual knitters who cannot afford or do not have the intention of investing much time or resources for organizing knitting projects themselves. They instead opt for a packaged set composed of yarn, tools, subsidiary materials and instructions available on internet shopping malls, despite the limited scope of variations allowed for knitters. As such, the plurality of motivations, purposes and engagements of knitters constitutes a major feature of Korean knitting practice, proving Warde (2005)'s point on the internally differentiated aspect of social practice in terms of understanding, skills and goals (139).

The most popular scheme adopted in internet knitting communities, designed to encourage the participation of members and to facilitate the communication of skills, know-how and knowledge is a group knitting project. This is a synchronized knitting project in which knitters knit the same patterns designated regularly by community management teams. An internet knitting community site owner explains the purpose of group knitting projects:

"It's more cooperative and stimulating than knitting on your own. You can post questions or pictures on community sites during the projects so that everybody can share solutions. It's also very interesting to see all the differences across the works of individual knitters which are based on the same pattern."

In summary, the rapid development of internet technology is exercising significant effects on knitting practice in Korea. As the popularization of group projects on the internet demonstrates, knitters continually adapt to the transformative material environments and formulate new conventions in knitting practice, suggesting the dynamic aspect of the practice. In the next section, how an array of feelings and emotions are formulated and mediated in connection with embodied experiences in knitting practice is investigated.

\section{Emotional Landscapes Constructed in the Embodied Experiences of Knitters}

\subsection{Emotional Effects of Knitting Practice}

Physical activities embedded in knitting induce various mental and emotional effects, which underpins the important content of knitting practice. The combination of simple and repetitive physical movements and control of the overall process by paying attention to regular changes within knitting patterns generate a state of high concentration. It is even described as a trance-like state, as if the knitting needle, yarn and body are integrated into one entity. The close interconnection between bodily activities and mental and emotional states is evidenced by one knitter' account.

"I use the computer all day at work, and I do not engage in any other physical activity. When I knit, I use my hands and these simple movements make me calm and focused and not easily distracted. I like seeing changes and patterns being created after making some simple purls and plains. But If I make even one mistake, it stands out quickly and directly affects the flow of the work. That's every interesting for me."

Many knitters interviewed point out that a high level of concentration on knitting projects helps ease the tensions and stresses encountered in daily life. Often, knitting is compared to having a meditative function, described as an alternative form of religion and spirituality (Murphy, 2002; Parkins, 2004:435). Parkins (2004) interprets the function of knitting as the resignification of the self by creating an alternative space as a move away from time-pressed and complex postmodern life (433-436). Knitting also seems to provide an alternative space, a kind of release from stressful situations in daily life for the knitters below.

"Before I started knitting, I used to be upset when my husband came home late. Now I knit at night. I feel far more poised, focusing on my work and am not very disturbed by my husband coming home late. It's really relaxing for my nerves and takes away my little worries and obsessions."

"I think I knit mainly for dealing with stress. Simple physical labor involving the use of the hands, such as the kind you can experience in activities like knitting or woodcraft, gives me a sense of comfort and helps reduce stress by releasing me from the complex and serious concerns of life.

Immersion in knitting projects can become so intense as to create anxiety for some knitters after the completion 
of a knitting project. They confess a sense of emptiness or feeling lost after a period of deep mental and physical engagement. This suggests that knitting can become an activity that does not arise out of necessity or has a clear purpose. However, knitters who have a lot of experience with knitting practice tend to say that long experience with knitting has enabled them to handle this urge to indulge in knitting, a typical symptom in the early stage of one's knitting career.

"Knitting is a kind of addiction or drug. I feel so bored and empty and a sense of being lost when I'm done with one project."

"For example, I check the time when a TV drama begins and I can stop knitting when the drama starts. When I first started knitting, I couldn't control my urge to keep knitting on and on, but now I can; otherwise I can't enjoy it as a pleasurable and long-term hobby. I still want to carry on when I sit for knitting, not wanting to stand up to wash the dishes, but now I can control myself."

Some knitters find a sociable environment with casual chats and shared interests more helpful for the flow of their knitting projects; conversely, they find knitting in an isolated environment rather tiresome. It is common to see knitters spending a long time, from the morning to the evening, in knitting shops and sharing delivered lunches with other knitters. The mixture of simple physical activities and sociability generates a sense of security and comfort, which has almost therapeutic effects for some knitters, like in the case of one interviewee who visits a wholesale knitting shop in the Dongdaemun Jonghap Market about 3-4 times a week despite the one-hour commute from home.

"It has been very stressful for me to stay home alone after quitting my job following my brain surgery a few years ago... But time flies here. After spending hours chatting, laughing, and knitting, I feel much happier and I'm also left with clothes, bags and pieces of work of my own...It's better than playing hwatu (a kind of card game), going to night clubs or gossiping with friends."

\subsection{Emotional Landscape among Middle Class Female Knitters}

As suggested by the above cases, knitting is also related to an alternative temporality. Although craft production is generally associated with slowness in the speedy pace of contemporary life (Note 6), it can operate in an opposite way. Involving highly attentive physical activities and the tangibility of the progress of knitting projects, knitting can offer a sense of accelerated time for those who are stressed by the lagging tempo of life. It is particularly pertinent for middle aged or senior full-time housewives who have difficulty dealing with a huge amount of free time after their children have grown up. The relativity of time derived from knitting can be considered in the context of middle class female domesticity, which is characterized by ample leisure time and the lack of social activities or a career. This can be assumed by the fact that the knitters encountered in the course of this research are predominantly middle class women and most of them list the relative quick tempo of time as a major appealing factor of knitting.

The temporality associated with knitting is also related to the sense of good management of time. Knitters feel that they spend time in a productive way and the feeling of producing something out of one's own labor provides a great sense of fulfillment. It is implied in the case of a regular local knitting shop visitor.

"When I come home after just chatting over lunch and coffee, I usually end up feeling that another day has been wasted. But when I come here and chat while knitting, I feel a sense of fulfillment and that time has been well spent. Also, I can gain pleasure from seeing my skills developing from one project to another."

To be able to have visible and lasting evidence of one's own labor, skill and knowledge and to confirm the progress of the practical understanding over different projects, is a strong motivation for continued engagement in knitting. The tangibility of productivity and the improvement of skills and know-how are particularly important for the knitters' evaluations of their everyday accomplishments. Knitting provides different feelings from doing other everyday routines such as housework, whose results evaporate quickly and involve the same process every day. Full-time housewives, who have some periods of free time during the day, such as when their children are at school or when their children receive music lessons, express their concern with managing their time well and feelings of being a productive person, which they cannot easily feel from doing housework or after an indulgent day of shopping.

\subsection{Emotions Derived from the Receptions of Knit Products by Other People}

Another major benefit of knitting is the pleasure of displaying the end products to other people and receiving recognition for their skills and taste. The majority of interviewees tell of an experience where their work was complimented or envied by other people. 
"I made a hanbok (Korean traditional costume) and a cap with scraps of yarn I used for my previous works, for my granddaughter. I went to a wedding with her in it and people there took pictures of her and said they're going to knit the same one."

"The biggest joy of knitting is that you can show what you knit easily to other people and get appreciation. You can take knitted clothing or bags with you wherever you go. But in other hobbies, you can't take things around. A knitter who also paints told me that she can't carry her paintings with her to show off but she can show off her knitted clothes."

Knitters often knit gifts for family members or close friends, and are very sensitive to the reaction to and treatment of gifts by the recipients as these gifts embody the time, physical labor and commitment they have invested in the whole process. One knitter mentions that after she experienced some unsatisfactory treatment of her knit gifts by the recipients, she now never gives her knit works to other people. Conversely, appreciation of the gift by other people is received as the confirmation of the good accomplishment of projects, signifying the good taste and skills of the knitter. Further, it also functions as material evidence of the recognition of the commitment and integrity of the knitters, which are regarded as a basis for close social relationships.

"It's much cheaper buying ready-made clothes than knitting them yourself. But I knit clothes for my children and husband because they are different from any other things you can buy in the world. You can do this only when you have affection for the wearers... I knit things as presents for those I am close to, and not so much for myself. Considering the time and money put into this, if I found out that someone didn't like my present, I would never knit for the person again."

As such, the materiality of knitting practice arising from physical performances and the use and production of material goods is closely related to an array of feelings and emotions produced both during the process and after the completion of a project. The experiences of this complex web of sensations and emotional states affect the shaping of the dispositions and careers of knitters and also by extension, the construction and dynamics of the whole knitting practice.

\section{Conclusion}

An examination of Korean knitting practice addressed some important aspects of contemporary consumption, consumer and everyday practice. It suggests the relevance of the emerging academic argument against the stereotyped categorization of the consumer and against the prioritization of the issues of identity formation, tastes or lifestyles in consumption studies (Gronow, Warde, 2001; Warde, 2005; Slater, Miller, 2007; Watson, Shove, 2008). Exploration of the materially-mediated dimension of knitting is also consonant with the rise of interest in the hybridity between subject and object, human and nonhuman, and the mental and physical.

Knitters are not governed by a single force and they are not a single active agent in the workings of knitting practice. They are, rather, part of the complex topography of knitting practice, which is based on the close relationship between humans, understanding and things. In addition, the plurality of knitters' motivations and engagement and the multifarious aspect of knitting practice which combines consumption, production, education and socialization in Korea, refers to the increasing ambiguity and heterogeneity of contemporary consumption and everyday life.

An overview of Korean knitting practice revealed that practical understanding is a critical force in the construction and persistence of knitting practice. It also demonstrated that the embodied activities and material relations situated in knitting practice produce a particular array of emotions and feelings that help configure the unique characteristics and qualities of the practice.

The transformative nature of the contemporary material conditions further complicates the geography of current knitting practice. The internet has been an active agent in transforming knitting practice significantly, affecting the way in which relations, networks and meanings are constituted and updated. However, the rapid development of technology imposes potential for the development of new phases and characteristics as well as instability for knitting practice. Thus, further research would be required to explore the new developments and consequences of the technological evolution.

This paper has briefly raised issues such as the role of aspirations for social capital and gender difference, but not in sufficient depth. How these elements mediate the everyday experiences of knitters would constitute an interesting and fruitful theme. Also, the impacts of the historical development of knitting material, particularly the technological innovations in knitting yarns in the shaping of the conventions within knitting practice, would be necessary for a more nuanced and closer look into this multi-layered yet dynamic social practice. 


\section{References}

Burrell, K. (2008). Managing, Learning and Sending. Journal of Material Culture, 13(1), 63-83.

Cambell, C. (2005). The Craft Consumer: Culture, Craft and Consumption in a Postmodern Society. Journal of Consumer Culture, 5(1), 23-42.

Cheil Industries. (1994). 40 years of history, Cheil Industries. Seoul: Cheil Industries.

Dante, T. (2004). The Driver-car. Theory, Culture \& Society, 21(4/5), 61-79.

Gronow, J., \& Warde, A. (Eds.) (2001). Ordinary Consumption. London, New York: Routledge.

Hye Rim, K. (2004). Song Young Ae, President of Banul Iyagi. [Online] Available: http://news2.kukinews.com/ article/view.asp?page $=1 \&$ gCode $=$ kmi\&arcid $=0919283075 \&$ code $=13220000$ (August 20, 2010).

Korea Textile Agency. (1973). Report on clothing consumption in 1973, Textile, 1973 May, 76-78.

Miller, D. (2005). Introduction. In Miller, D. (Eds.), Materiality. Durham, London: Duke University Press. 1-50.

Minahan, S., \& Wolfram, C. J. (2007). Stitch'nBitch: Cyberfeminism, a Third Place and the New Materiality. Journal of Material Culture, 12(1), 5-21.

Murphy, B. (2002). Zen and the Art of Knitting. Avon, Massachusetts: Adams Media Corporation.

Myzelev, A. (2009). Whip your Hobby into Shape: Knitting, Feminism and Construction of Gender, Textile, 7(2), 148-163.

Parkins, W. (2004). Celebrity Knitting and the Temporality of Postmodernity. Fashion Theory, 8(4), 425-442.

Reckwitz, A. (2002). Towards a Theory of Social Practices: A Development in Culturalist Theorizing. European Journal of Social Theory, 5(2), 243-263.

Schatzki, T., Cetina, K. K., \& Savigny, E. V. (2001). Introduction. In Schatzki, T. (Eds.), The Practice Turn in Contemporary Theory. London, New York: Routledge. 1-14.

Sheller, M. (2004). Automotive Emotions. Theory, Culture \& Society, 21(4/5), 221-242.

Slater, D., \& Miller, D. (2007). Moments and Movements in the Study of Consumer Culture: A Discussion between Daniel Miller and Don Slater. Journal of Consumer Culture, 7(1), 5-23.

Warde, A. (2005). Consumption and Theories of Practice, Journal of Consumer Culture, 5(2), 131-153.

Watson, M., \& Shove, E. (2008). Product, Competence, Project and Practice. Journal of Consumer Culture, 8(1), 69-89.

Wilkinson-Weber, C. M. (2010). From Commodity to Costume: Productive Consumption in the Making of Bollywood Film Looks. Journal of Material Culture, 15(1), 3-29.

Williams, C. C. (2004). A Lifestyle Choice? Evaluating the Motives of Do-It-Yourself (DIY) Consumers. International Journal of Retail \& Distribution Management, 32(5), 270-278.

\section{Notes}

Note 1. According to Cheil Industries, Korea's largest producer of clothing materials and clothing, the sales figure of yarns for hand knitting dropped dramatically since 1987 whereas that of machine knitting yarns remained steady. The company attributes the decrease of demand for hand knitting yarns to the change of consumers' lifestyles (Cheil Industries, 1994, 282).

Note 2. For example, an interview with Korea's largest knitting room chain 'Song Young Ae'sBanul Iyagi (Song Young Ae's Needle Story), which operate both off-line and on-line knitting shops (http://www.banul.co.kr), revealed that the chain has about 200,000 members registered for its internet shopping malls. The chain's turnover for 2004 was 2 billion won (Kim, 2004), but it is expected to increase to 5 billion won (about 4 million dollars) in 2010.

Note 3. The interviews were carried out from April to August in 2010.

Note 4. According to the survey by IWS (International Wool Secretariat) Korea office in 1973, 50.9\% of male consumers and $57.2 \%$ of female consumers still bought customized clothing. The survey also showed that consumers were not particularly satisfied with the quality of material, sewing or finishing of mass-produced clothing (Korea Textile Agency, 1973, 77-8). In addition, the interviews with senior knitters, who shared their memories of the past decades, support the prominence of the practical aspect of knitting practice before the industrialization of Korea. 
Note 5. During the economic crisis of Korea in 1997, caused by the shortage of foreign exchange and the downgrading of the credibility of the Korean economy, the Korean government sought an emergency loan from IMF (International Monetary Fund). This had tremendous effects on the economic and social structures of Korea, generating the dramatic increase of bankruptcy and the unemployment rate.

Note 6. Wendy Parkins(2004) explores the alternative sense of time experienced in knitting practice from a perspective of knitting as a way of creating space and time for the self in the context of domesticity by escaping the speed and complexities of postmodern life (pp. 432-43).

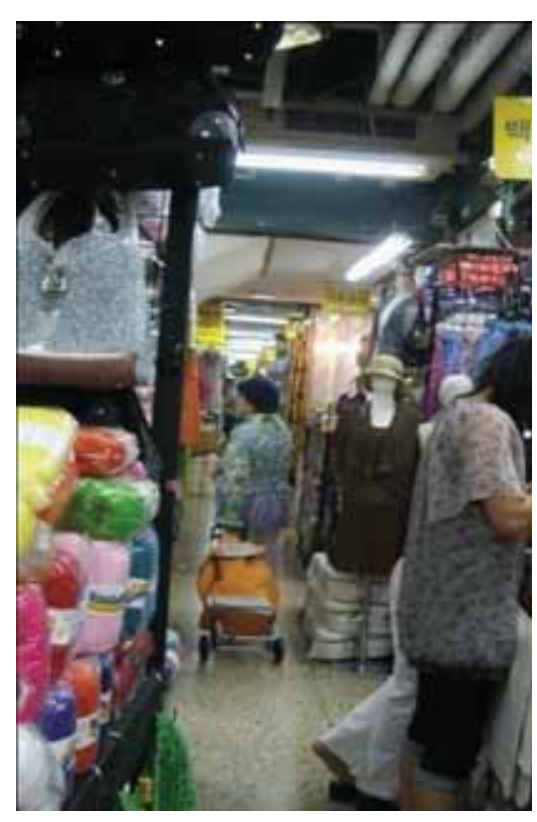

Figure 1. wholesale knitting shops in the Dongdaemun Jonghap Market, Seoul

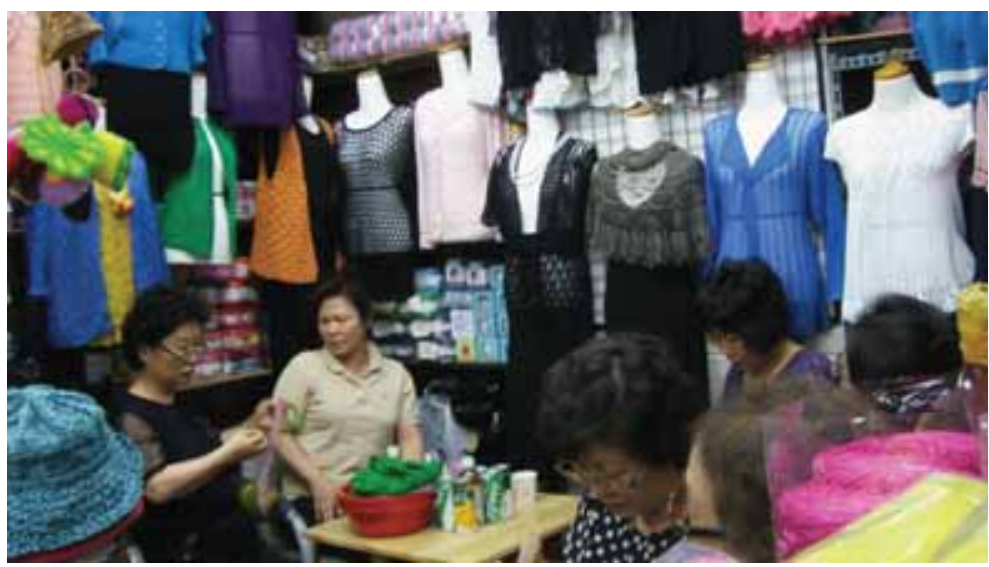

Figure 2. knitters in a wholesale knitting shop in the Dongdaemun Jonghap Market, Seoul

Photograph by Hye Young Shin

Photograph by Hye Young Shin

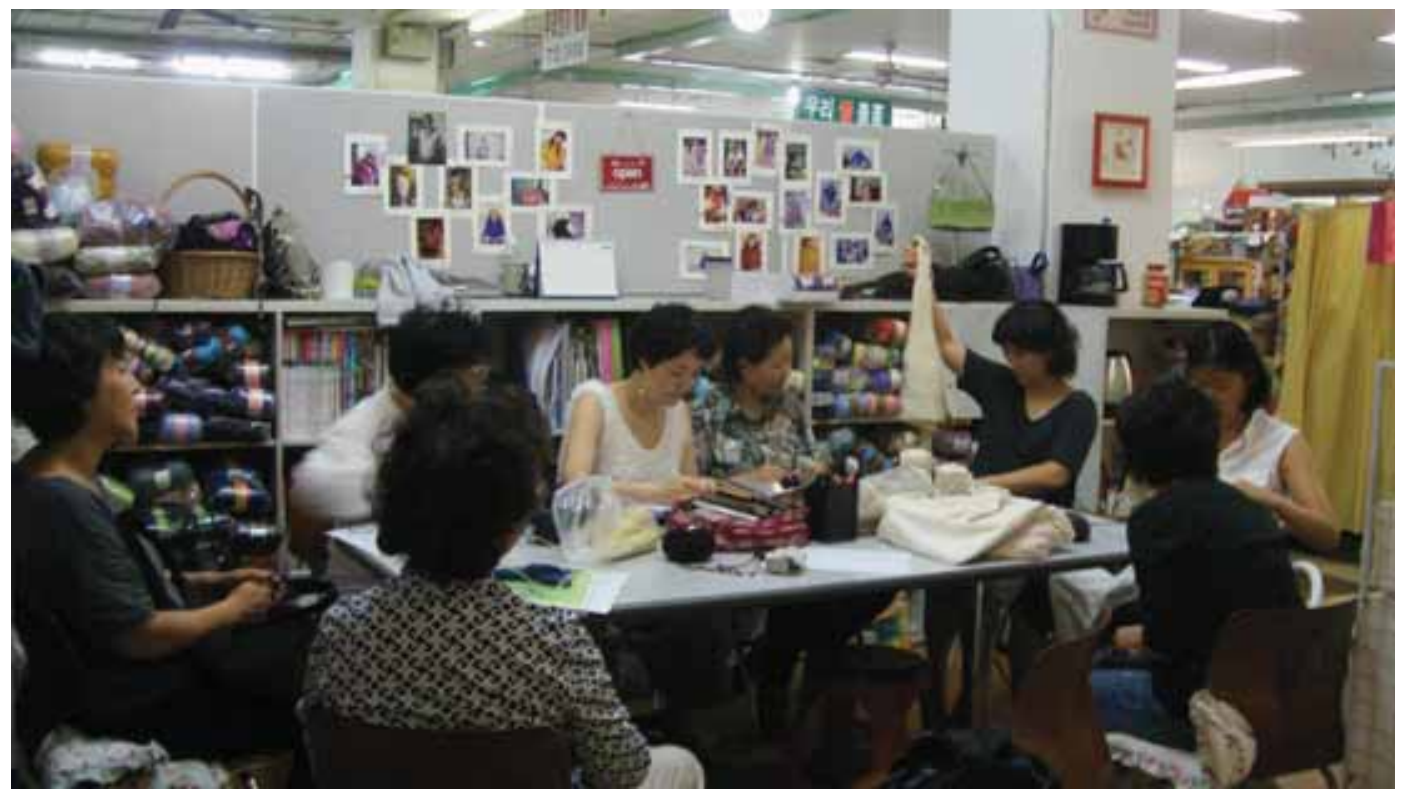

Figure 3. knitters in a retail knitting shop in Bundang, a city near Seoul

Photograph by Hye Young Shin 


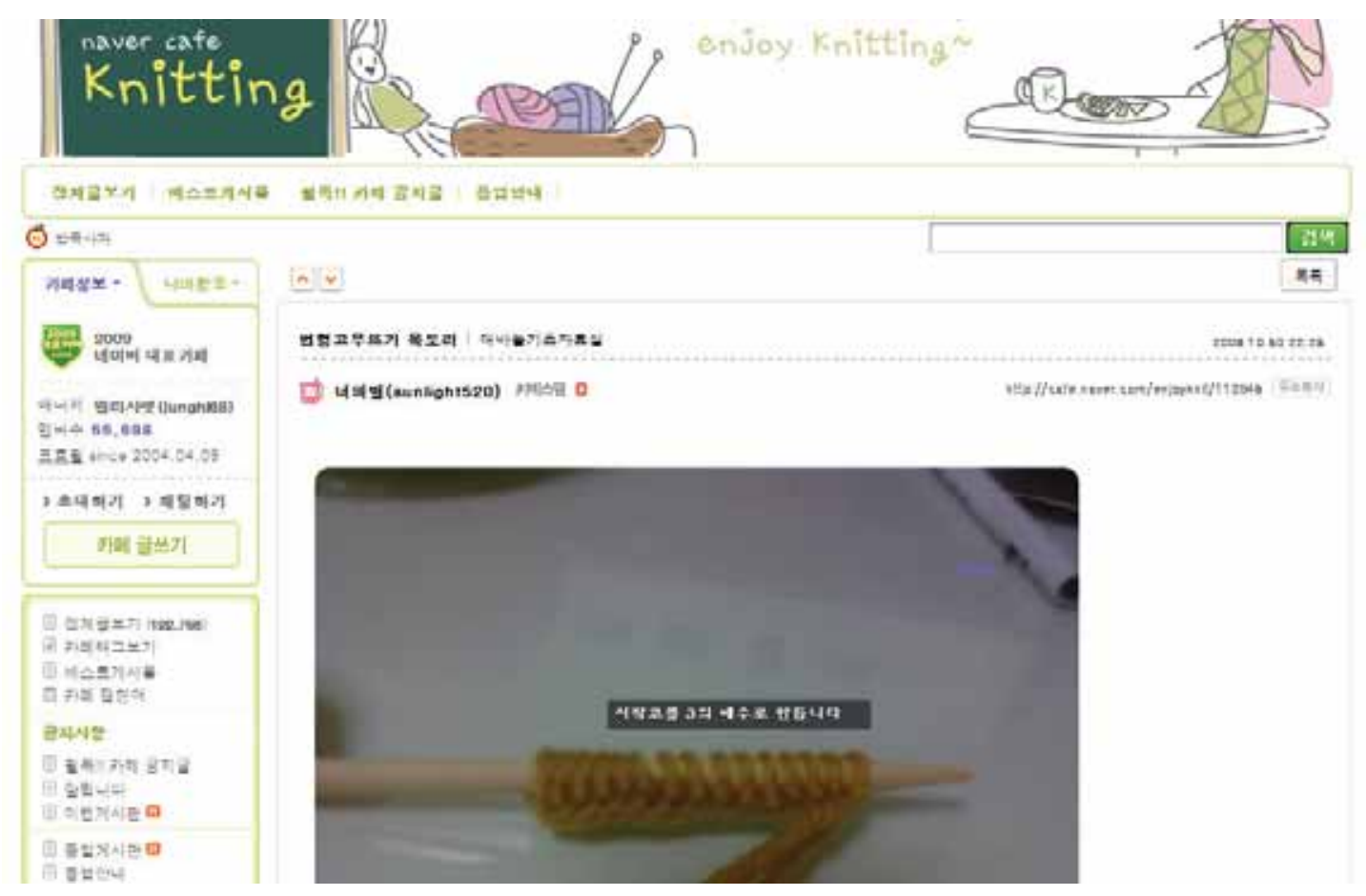

Figure 4. An illustrated instruction posted in the learning section on an internet knitting community page (http://cafe.naver.com/enjoyknit)

A captured image of the internet page of a knitting community

Reproduced with permission 